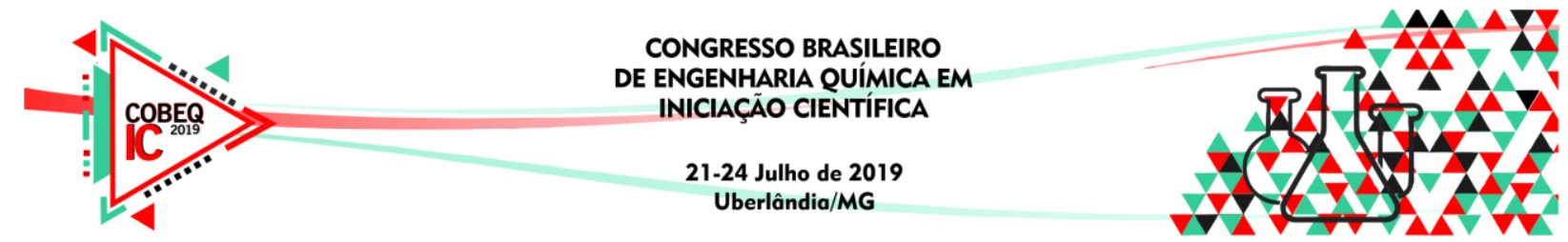

\title{
ATIVAÇÃO DA BENTONITA PARAÍBA COM CARBONATO DE SÓDIO PARA APLICAÇÃO EM FLUIDOS DE PERFURAÇÃO
}

\author{
M.M. SCHARF ${ }^{1}$, G.I. ALMERINDO ${ }^{1}$ e J. MAGALHÃES ${ }^{2}$ \\ ${ }^{1}$ Universidade do Vale do Itajaí, Engenharia Química \\ ${ }^{2}$ AMC do Brasil, Drilling Optimisation \\ E-mail para contato: ${ }^{1}$ marianamscharf@ gmail.com; gizelle.almerindo@ univali.br; \\ juliano.Magalhes@imdexlimited.com
}

\begin{abstract}
RESUMO - A ativação de bentonitas visa agregar valor àquelas de procedência natural que não apresentam aplicações industriais. A empresa AMC do Brasil utiliza bentonitas provenientes da Paraíba, porém são ativadas com carbonato de sódio para aplicação como fluidos de perfuração. Há o interesse de ampliar os teores de carbonato de sódio, na concentração API $\left(46,3 \mathrm{~g} \mathrm{~L}^{-1}\right)$, recomendada pela norma API 13A e 13B em caracterizações de viscosidade pelo Instituto Americano de Petróleo. Portanto, no presente trabalho, a bentonita proveniente da Paraíba com granulometria retida na peneira Tyler de mesh 100 (com abertura de $0,149 \mathrm{~mm}$ ) foi ativada com carbonato de sódio com teores de 1 a $10 \%$. O ensaio revelou um aumento significativo da capacidade de troca catiônica, bem como da viscosidade da argila utilizada, sendo os valores encontrados entre 4 a $10 \mathrm{cP}$. O teste de Tukey demonstrou que a viscosidade não alterou para teores de 4 a $10 \%$, e a capacidade de troca cationnica adquiriu valores semelhantes entre 3 e 10\%, sendo $4 \%$ de adição de carbonato de sódio suficiente. A área superficial da argila apresentou uma redução de $37 \%$ quando comparada a não ativada. Com a viscosidade obtida há uma possível utilização de bentonitas de baixo valor agregado para aplicações mais nobres, como parte integrante de fluido de perfuração.
\end{abstract}

\section{INTRODUÇÃO}

A empresa AMC do Brasil (Itajaí - SC) é especializada na fabricação de produtos para perfuração e manutenção de poços em geral. Dentre os fluidos de perfuração comercializados pela empresa tem-se a bentonita. Esta é uma argila plástica constituída principalmente por argilominerais do grupo das esmectitas (ARANHA et al, 2004).

Aranha et al (2004), afirmam que o alto aproveitamento industrial das bentonitas é resultado de suas características, como: partículas muito finas, elevada carga superficial, alta capacidade de troca catiônica (CTC), elevada área superficial e inchamento (afastamento de suas camadas) na presença de água. Porém, os autores ressaltam que as propriedades das bentonitas variam muito e nem todas são interessantes comercialmente. Além disso, muitas apresentam propriedades apropriadas para um uso, enquanto para outro são inadequadas. $\mathrm{O}$ motivo de tais diferenças nas propriedades está relacionado com a composição da esmectita e a natureza de seus cátions trocáveis. 


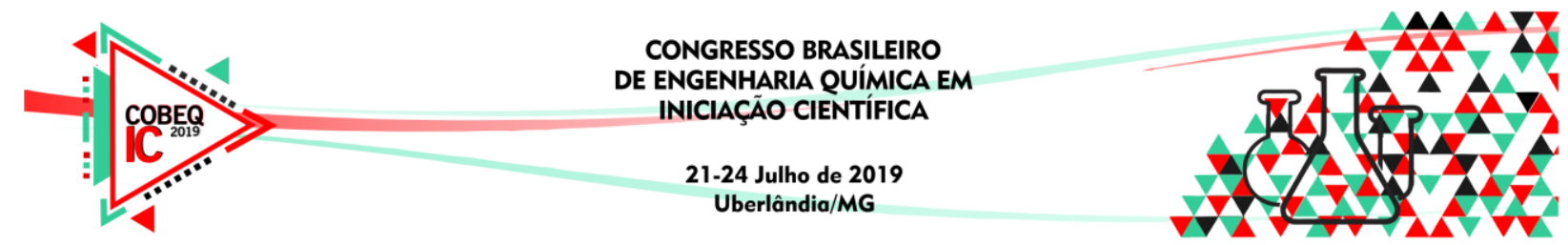

Bentonitas com a viscosidade e tixotropia adequadas podem ser utilizadas como agentes controladores da viscosidade de um fluido de perfuração, transportando com maior eficiência fragmentos de rochas para a superfície (AMORIM et al, 2006). No processo de ativação das bentonitas pode-se usar diferentes teores de carbonato de sódio $\left(\mathrm{Na}_{2} \mathrm{CO}_{3}\right)$ sendo que na empresa AMC do BRASIL são utilizados teores entre 1 e $2 \%$. Entretanto, devido à disponibilidade de bentonitas e a possibilidade diante de diversas aplicações, a AMC do BRASIL juntamente com nosso grupo de pesquisa tem o interesse de investigar teores diferentes do que comumente utiliza.

Na literatura diversos métodos de ativação são propostos (ARAÚJO; MACHADO, 2002; KARIMI; SALEM, 2011; SALEH; MAHASNEH, 2015; YILDIZ, ÇALIMLI, 2001), mas há dados escassos sobre métodos de ativação na concentração API (46,3 g L-1), indicada pelo Instituto Americano de Petróleo (AMERICAN PETROLEUM INSTITUTE, 2005). Para tanto, numa parceria indústria e academia, o presente trabalho objetiva avaliar a cinética de ativação da bentonita proveniente da Paraíba com granulometria retida em mesh 100 (abertura de $0,149 \mathrm{~mm}$ ), com porcentagens entre 1 e $10 \%$ de carbonato de sódio, visando alcançar propriedades que atendam as aplicações da empresa AMC do Brasil.

\section{METODOLOGIA}

\subsection{Preparo das Amostras}

A moagem da argila foi realizada por 20 minutos em moinho de bolas (MA 500 da Marconi). Em seguida, a amostra foi peneirada no agitador de tamises sendo a granulometria determinada mediante peneiras Tyler. A bentonita retida na malha de mesh 100 (com abertura de $0,149 \mathrm{~mm}$ ) foi solubilizada em água na concentração API 13A $\left(46,3 \mathrm{~g} \mathrm{~L}^{-1}\right)$.

\subsection{Caracterização da Argila não Ativada e Ativada}

2.2.1Área Superficial Específica - Adsorção Física de Nitrogênio: A amostra foi submetida a tratamento térmico $\left(110^{\circ} \mathrm{C} / 1 \mathrm{~h}\right)$ sob vácuo para a eliminação de umidade e demais voláteis. $\mathrm{O}$ processo de adsorção de $\mathrm{N}_{2}$ foi realizado na temperatura do nitrogênio líquido $\left(-196^{\circ} \mathrm{C}\right)$ no equipamento Nova 2200e (Quantachrome). O valor da área superficial específica foi determinado pelo método de BET - Brunauer-Emmett-Teller.

2.2.2 Teste de Viscosidade: A viscosidade aparente e plástica foi verificada com viscosímetro Fann 800 (OFITE) segundo a norma 13B-2 (AMERICAN PETROLEUM INSTITUTE, 2005). A viscosidade foi analisada em triplicata.

2.2.4 Capacidade de Troca Catiônica (CTC): A capacidade de troca catiônica foi realizada segundo a norma 13B-2 (AMERICAN PETROLEUM INSTITUTE, 2005). Inicialmente, foi preparada uma solução de azul de metileno na concentração $1 \mathrm{~g} / \mathrm{L}$ (Solução 1). Uma segunda solução (2) contendo ácido sulfúrico, água, peróxido de hidrogênio e argila também foi preparada. Com o auxílio de uma pipeta, a solução que contém a argila foi saturada com $1 \mathrm{ml}$ de azul de metileno. Uma gota desta mistura saturada foi colocada em papel filtro. Na ausência de formação de uma auréola de azul de metileno ao redor da gota no papel filtro adicionou-se uma maior quantidade da solução de azul de metileno à solução que 


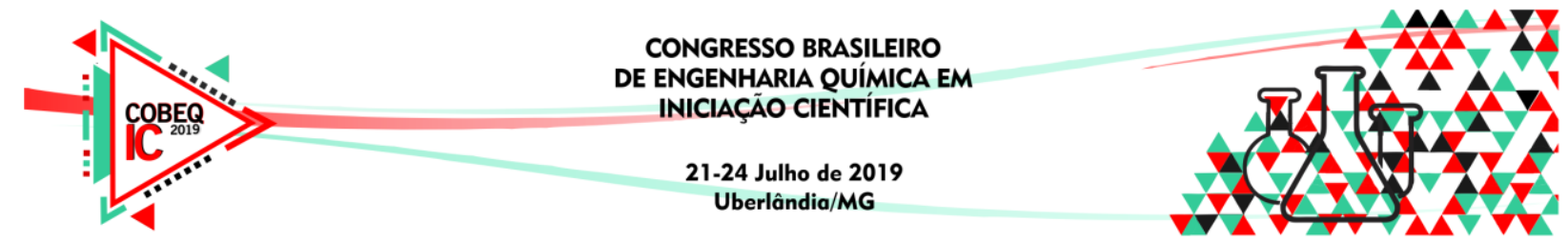

contém a argila. Ao ser formada a auréola tem-se a interrupção da adsorção do azul de metileno na solução contendo a argila. A capacidade de troca catiônica é representada em mili equivalentes por $100 \mathrm{~g}$ (meq/100g), ao qual pode ser calculada pela equação abaixo:

$$
\operatorname{CTC}\left(\frac{\text { meq }}{100 g}\right)=\frac{\text { volume de azul de metileno }(\mathrm{ml})}{\text { massa da amostra de bentonita utilizada }(g)}
$$

Sendo a massa calculada pelos $2 \mathrm{ml}$ utilizados da solução de bentonita em concentração API $\left(46,3 \mathrm{~g} \mathrm{~L}^{-1}\right)$. A capacidade de troca catiônica foi realizada em quintuplicata.

\subsection{Cinética de Ativação}

A ativação com 1 a $10 \%$ de carbonato de sódio, foi realizada de acordo com adaptações da metodologia apresentada por KARIMI \& SALEM (2011). Para tanto, a mistura em concentração API recomendada pela norma 13-A e 13-B $\left(46,3 \mathrm{~g} \mathrm{~L}^{-1}\right)$ foi misturada, inicialmente, com $1 \%$ de carbonato de sódio por 110 minutos à temperatura ambiente. A cinética de ativação foi analisada pela viscosidade conforme descrito no item 2.2.3 a cada vinte minutos, iniciando em 10 minutos de ativação. Este procedimento foi realizado a cada $1 \%$ carbonato de sódio adicionado até um máximo 10\%. No tempo final de cada porcentagem, analisou-se a capacidade de troca catiônica da bentonita recém ativada (item 2.2.4).

\subsection{Secagem da Bentonita Ativada}

A metodologia de secagem das bentonitas foi adaptada de MACHADO \& ARAÚJO (2002). A bentonita ativada foi seca em estufa com circulação de ar (Nova Ética - modelo 4000.5) na temperatura de $95^{\circ} \mathrm{C}$ até obtenção de massa constante.

\subsection{Análise Estatística}

Os dados de viscosidade e capacidade de troca iônica foram interpretados mediante Análise de Variância (ANOVA), utilizando-se teste $\mathrm{F}$ ao nível de significância de $5 \%$. As médias dos valores foram comparadas mediante teste Tukey a nível de $5 \%$ de significância, utilizando o Software Minitab 18 como ferramenta para análise.

\section{RESULTADOS E DISCUSSÕES}

$\mathrm{Na}$ ausência de carbonato de sódio os valores da viscosidade e da capacidade de iônica encontrados foram de 3,7 $\pm 0,5 \mathrm{cP}$ e 54,0 $\pm 9,6 \mathrm{meq} / 100 \mathrm{~mL}_{\mathrm{AM}}$, respectivamente. Já para a quantidade máxima utilizada (10\%) obteve-se um valor de 9,0 $\pm 1,4 \mathrm{cP}$ e 110,2 $\pm 10,6$ meq/100mLAM. Portanto, verifica-se uma diferença entre a presença e a ausência do agente ativante mesmo com o valor do desvio padrão significativo. Vale mencionar que o erro de leitura do aparelho de viscosidade é de $\pm 1 \mathrm{cP}$ e que os valores obtidos são baixos devido concentração recomendada na API 13 A (46,3 g/L). Se, por exemplo, fosse utilizado $100 \mathrm{~g} / \mathrm{L}$, as leituras de viscosidade seriam muito mais altas e assim os erros associados seriam minimizados. 
Por meio do teste ANOVA, verificou-se que para a ativação com 1 a $10 \%$ de carbonato de sódio, as médias de capacidade de troca catiônica e viscosidade apresentaram diferença significativa $(\mathrm{p}<0,05)$. O teste Tukey mostrou que os resultados de viscosidade entre 4 e $10 \%$ de carbonato de sódio, não diferiram significativamente entre si, o que representa que $4 \%$ pode ser definido como quantidade suficiente. As médias de viscosidade das ativações realizadas entre 2 e $9 \%$ de carbonato de sódio, assim como, 0 e $9 \%$ também não diferiram entre si. Os resultados de capacidade de troca catiônica não diferiram significativamente entre si entre 3 e $10 \%$ de carbonato de sódio. Portanto, $3 \%$ pode ser definido como quantidade suficiente. $\mathrm{O}$ mesmo ocorreu entre 1 e $8 \%$, assim como, 0 e $2 \%$.

Tabela 1 - Análise estatística da viscosidade aparente (cP) em L600 $\left(\mathrm{Na}_{2} \mathrm{CO}_{3}\right.$ entre 0 e $\left.10 \%\right)$.

\begin{tabular}{|c|c|c|}
\hline Fonte & GL & Valor - P \\
\hline \hline Repetição & 2 & 0,787 \\
\hline Matriz & 10 & 0,001 \\
\hline Erro & 20 & \\
\hline Total & 32 & \\
\hline
\end{tabular}

\begin{tabular}{|c|c|c|c|c|c|c|}
\hline Matriz & N & Média & Desvio Padrão & \multicolumn{3}{|c|}{ Agrupamento } \\
\hline 10 & 3 & 10,33 & 0,47 & A & & \\
\hline 9 & 3 & 9,00 & 0,94 & A & B & \\
\hline 8 & 3 & 8,67 & 0,47 & A & B & C \\
\hline 7 & 3 & 8,33 & 3,09 & A & B & C \\
\hline 6 & 3 & 7,33 & 0,47 & A & B & C \\
\hline 5 & 3 & 7,33 & 0,94 & A & B & C \\
\hline 4 & 3 & 7,00 & 0,47 & A & B & C \\
\hline 3 & 3 & 4,67 & 1,70 & & B & C \\
\hline 2 & 3 & 4,67 & 1,25 & & B & C \\
\hline 1 & 3 & 3,67 & 1,63 & & & C \\
\hline 0 & 3 & 3,67 & 1,41 & & & C \\
\hline
\end{tabular}

Médias que não compartilham uma letra são significativamente diferentes.

Tabela 2 - Análise estatística da CTC com porcentagens de $\mathrm{Na}_{2} \mathrm{CO}_{3}$ entre 0 e $10 \%$.

\begin{tabular}{|c|c|c|}
\hline Fonte & GL & Valor - P \\
\hline \hline Repetição & 4 & 0,985 \\
\hline Matriz & 10 & 0,000 \\
\hline Erro & 40 & \\
\hline Total & 54 & \\
\hline
\end{tabular}

\begin{tabular}{|c|c|c|c|c|c|c|}
\hline Matriz & N & Média & Desvio Padrão & \multicolumn{3}{|c|}{ Agrupamento } \\
\hline 10 & 5 & 110,151 & 9,659 & A & & \\
\hline 9 & 5 & 107,991 & 23,262 & A & & \\
\hline 8 & 5 & 97,192 & 9,659 & A & B & \\
\hline 7 & 5 & 95,032 & 5,290 & A & B & \\
\hline 6 & 5 & 90,713 & 9,659 & A & B & \\
\hline 5 & 5 & 86,393 & 4,320 & A & B & \\
\hline 4 & 5 & 86,393 & 4,320 & A & B & \\
\hline 3 & 5 & 84,233 & 17,547 & A & B & \\
\hline 2 & 5 & 71,274 & 11,830 & & B & C \\
\hline 1 & 5 & 69,114 & 11,830 & & B & C \\
\hline 0 & 5 & 53,996 & 10,581 & & & C \\
\hline
\end{tabular}




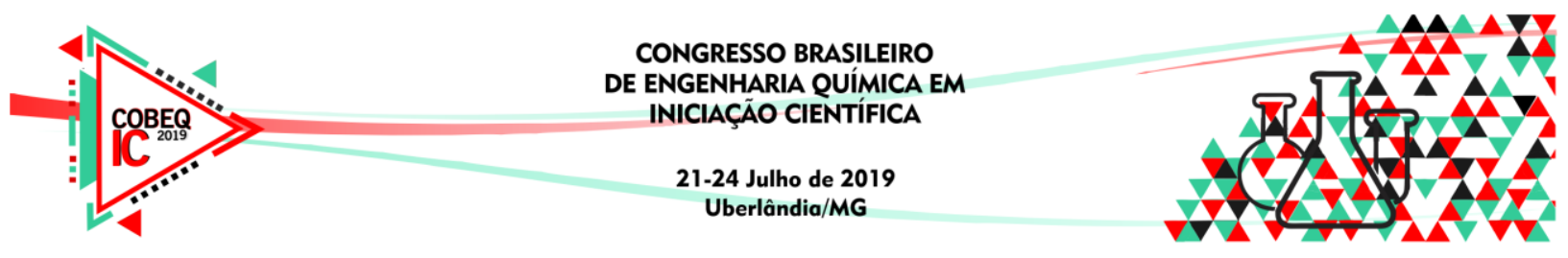

É possível observar na Tabela 1 que os valores de viscosidade obtidos são inferiores à $30 \mathrm{cP}$ em $600 \mathrm{rpm}$, estipulados pelo Instituto Americano de Petróleo (API, 2005). Segundo Souza (1928), valores de viscosidade abaixo de $15 \mathrm{cP}$, em dispersões de $6 \%$ em água, são comuns em bentonitas brasileiras, porém elas atingem o mínimo necessário para utilização industrial. Com os resultados experimentais apresentados na Tabela 1, é possível perceber que a ativação atingiu níveis satisfatórios de viscosidade, demonstrando a possibilidade de utilização de argilas com baixo valor comercial em aplicações mais nobres, como para fluido de perfuração em exploração mineral, que requer valores de viscosidade acima de $10 \mathrm{cP}$ (600 rpm) para ser considerado comercialmente viável (adaptado das especificações API).

Os valores de capacidade de troca catiônica obtidos na ativação (Figura 2) estão dentro do esperado para bentonitas (de 60 a $170 \mathrm{meq} / 100 \mathrm{~g}$ ), sendo a presença de contaminantes um importante fator para variação dos dados observados (ARANHA et al, 2004). O alto desvio padrão pode estar associado a não homogeneidade da amostra durante a coleta ou devido impurezas que podem ser encontradas tanto na argila bentoníticas.

Outra melhora significativa observada foi o inchamento da bentonita em água, que melhorou a partir de $1 \%$ de ativação, aumentando com as maiores porcentagens de carbonato de sódio. A presença de íons sódio permite a maior adsorção de moléculas de água, demonstrando que a metodologia utilizada é adequada para ativação. Para a aplicação em fluidos de perfuração, elevadas áreas superficiais são características necessárias em argilas bentoníticas, tornando a análise de área superficial específica (BET) importante (ARANHA et al, 2004). A Tabela 1 apresenta as áreas superficiais da Paraíba ativada e não ativada, assim como, das bentonitas Chocolate, Verde Lodo e Bofe.

Tabela 1 - Áreas superficiais das bentonitas.

\begin{tabular}{|c|c|}
\hline Bentonitas & $\mathrm{S}_{\mathrm{BET}}\left(\mathrm{m}^{2} \mathrm{~g}^{-1}\right)$ \\
\hline \hline Paraíba não ativada & 64,1 \\
\hline Paraíba ativada $10 \%$ & 23,7 \\
\hline
\end{tabular}

O processo de secagem interferiu no produto final, formando pequenas placas, sendo necessária a moagem para obtenção do produto em pó, possivelmente interferindo, desta forma, na área superficial da argila que foi menor quando comparada a não ativada. Ainda, estudos mostram que a troca do íon $\mathrm{Ca}^{+2}$ para $\mathrm{Na}^{+}$, devido a ativação, ocasionam uma diminuição da área do microporo, reduzindo assim a área superficial específica em amostras tratadas com $\mathrm{Na}_{2} \mathrm{CO}_{3}$ (AMORIM et al, 2006). A diminuição da área superficial pode estar associada também ao processo de peptização, causado pelo contato da argila com água em presença de sais, provocando a coagulação em pH próximo à seis (BERGAYA et al, 2006). Ainda, para uma menor granulometria pode-se também submeter a amostra a moagem cujo tempo e número de esferas na moagem mecânica de alta energia possuem papel importante.

\section{CONSIDERAÇÕES FINAIS}

A ativação resultou na alteração significativa das propriedades de viscosidade e capacidade de troca catiônica. Utilizando o teste de Tukey é possível perceber que em $4 \%$ de adição de carbonato de sódio a viscosidade passou de $4 \mathrm{cP}$ para $10 \mathrm{cP}$ (em L600). O mesmo teste demonstrou que a capacidade de troca catiônica não diferira significativamente entre si 


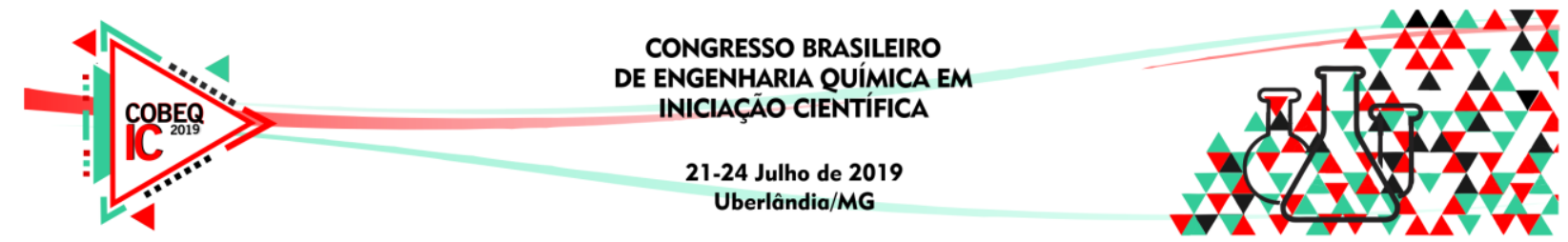

entre 3 e $10 \%$ de carbonato de sódio, gerando um aumento de 54 meq/100 g para 110,1 meq/100 $\mathrm{g}$ de azul de metileno. Foi observado também o inchamento da bentonita em água, que melhorou a partir de $1 \%$ de ativação, aumentando com maiores porcentagens de carbonato de sódio. Ainda, verificou-se uma diminuição de $37 \%$ na área superficial específica quando comparada a bentonita não ativada. Com os resultados encontrados é possível a utilização de argilas com baixo valor comercial em aplicações mais nobres, como parte integrante em fluidos de perfuração em exploração mineral.

\section{REFERÊNCIAS}

AMERICAN PETROLEUM INSTITUTE. Recommended practice for Field Testing Waterbased Drilling Fluids - 13B-2, 4. ed., Dallas, 2005.

AMORIM, L. V. et al. Estudo comparativo entre variedades de argilas bentoníticas de Boa Vista, Paraíba. Revista Matéria, v. 11, n. 1, p. 30-40, Campina Grande, UFCG: 2006.

ARANHA, I. B.; BALTAR, C. A. M.; LUZ, A. B. Caracterização, ativação e modificação superficial de bentonitas brasileiras. Comunicação Técnica. Centro de Tecnologia Mineral. Rio de Janeiro: CETEM, 2004.

BERGAYA, F.; THENG, B. K. G.; LAGALY, G. Handbook of Clay Science, Developments in Clay Science, Vol. 1, 2006.

KARIMI, L.; SALEM, A. Analysis of bentonite specific surface area by kinetic model during activation process in presence of sodium carbonate. Microporous and Mesoporous Materials, Irã, v. 141, n. 1-3, p. 81-87, 2011.

MACHADO, A. O. D. V.; ARAÚJO, J. M. M. Influência do carbonato de sódio em dispersões de bentonita. Anais do XIX Encontro Nacional de Tratamento de Minérios e Metalurgia Extrativa, v. 1, p. 570-573, 2002.

NETO, A. F. de A.; VIEIRA, M. G. A.; SILVA, M. G. C. da. Caracterização Térmica de Argilas Bentoníticas Destinadas à Remoção de Metais. VI Conferência Brasileira sobre Temas de Tratamento Térmico, São Paulo, 2012.

SALEH, S. K.; MAHASNEH, M. A. Activation of Jordanian Ore Bentonite by Sodium Carbonates. Journal of Minerals and Materials Characterization and Engineering, Jordânia, v. 3, n. 06, p. 477, 2015.

DE SOUZA SANTOS, Pérsio; SANTOS, Helena Souza. Ciência e tecnologia de argilas. E. Blucher, 1989.

YILDIZ, N.; ÇALIMLI, A. Alteration of Three Turkish Bentonites by Treatment with $\mathrm{Na} 2 \mathrm{CO} 3$ and H2SO4. Turkish Journal of Chemistry, Irã, v. 26, n. 3, p. 393-402, 2002 